\title{
Acoustic Emission for Identification of the Dominant Stress Component in Polymer Composites at Early Loads ${ }^{+}$
}

\author{
Kalliopi-Artemi Kalteremidou *, Dimitrios G. Aggelis ${ }^{1}$, Danny Van Hemelrijck ${ }^{1}$ and Lincy Pyl \\ 1 \\ 1 Dept. of Mechanics of Materials and Constructions (MeMC), Vrije Universiteit Brussel, Pleinlaan 2, 1050 \\ Brussels, Belgium, Dimitrios.Aggelis@vub.be (D.G.A.), Danny.Van.Hemelrijck@vub.be (D.V.H.), \\ Lincy.Pyl@vub.be (L.P.) \\ * Correspondence: Kalliopi-Artemi.Kalteremidou@vub.be \\ † Presented at 1st International Electronic Conference on Applied Sciences, 10-30 November 2020; Available \\ online: https://asec2020.sciforum.net/.
}

Published: 10 November 2020

\begin{abstract}
Carbon Fiber Reinforced Polymer (CFRP) composites are broadly used in many engineering applications. Their inherent anisotropy due to different fiber orientations in the individual layers can be considered an advantage since the maximum strength of the composite component can be designated in preferential loading directions. However, this anisotropy leads to multiaxial stress conditions at the same time, complicating the damage sequence and the mechanical response of CFRPs. Identification of these multiaxial conditions at early loading stages is of paramount importance in order to predict the upcoming structural response of the material. Acoustic Emission (AE) is applied in this study to various CFRP composite laminates with different stacking sequences, in which different multiaxial conditions are generated. Laminates consisting of 30 o off-axis plies are characterized by dominant shear stresses, whereas in laminates with $60 \mathrm{o}$ layers transverse normal stresses govern the stress state. Through quasi-static and incremental loading, it is shown through this research work that certain $\mathrm{AE}$ features can be used in order to identify the dominant stress component rather than just the occurring damage mode even at early loading stages, before severe fracture influences the mechanical capacity of the material. This is of great importance in cases that detrimental shear stresses are generated in the material, leading to important interlaminar delaminations and mechanical deterioration. AE can be used in this direction in order to predict the upcoming damage modes and to take the necessary measures to avoid final catastrophic failure.
\end{abstract}

Keywords: polymer composites, acoustic emission, multiaxiality, shear, Kaiser effect

Publisher's Note: MDPI stays neutral with regard to jurisdictional claims in published maps and institutional affiliations.

2020 by the authors. Submitted for possible open access publication under the terms and conditions of the Creative Commons Attribution (CC BY) license (http://creativecommons.org/licenses/by/4.0/). 